\title{
Metagenomic Analysis of Riesling Grapevine Reveals a Complex Virome Including Two New and Divergent Variants of Grapevine leafroll-associated virus 3
}

\author{
Huogen Xiao, ${ }^{1}$ Caihong Li, ${ }^{1}$ Maher Al Rwahnih, ${ }^{2}$ Valerian Dolja, ${ }^{3}$ and Baozhong Meng ${ }^{1 \dagger}$ \\ ${ }^{1}$ Department of Molecular and Cellular Biology, University of Guelph, Guelph, Ontario N1G 2W1, Canada; ${ }^{2}$ Department of Plant \\ Pathology, University of California, Davis, CA 95616, U.S.A.; and ${ }^{3}$ Department of Botany and Plant Pathology, Center for Ge- \\ nome Research and Biocomputing, Oregon State University, Corvallis, OR 97331, U.S.A.
}

\begin{abstract}
The virome of a major white wine grape of cultivar Riesling showing decline and leafroll disease symptoms was analyzed through highthroughput sequencing (HTS) using total RNAs as templates and the Illumina HiSeq 2500 platform. Analysis of HTS data revealed the presence of five viruses and three viroids in the infected vine. These viruses are Grapevine leafroll-associated virus 1 (GLRaV-1) and GLRaV-3 (genus Ampelovirus, family Closteroviridae) and three viruses of the family Betaflexiviridae (namely, Grapevine virus A [GVA], Grapevine virus $B$, and Grapevine rupestris stem pitting-associated virus [GRSPaV]). We also show that multiple distinct strains of three viruses (GLRaV-3, GVA, and GRSPaV) were present in this diseased grapevine. The complete genomes of two novel and highly divergent isolates of GLRaV-3 were determined using the draft genomes derived from HTS data and two independent rapid amplification of cDNA ends (RACE) strategies to obtain sequences at both the $5^{\prime}$ and the $3^{\prime}$ termini of the viral genomes.

Questionable genome regions of both isolates were also verified through cloning of reverse transcription polymerase chain reaction products and Sanger sequencing. These two isolates are vastly divergent from all other isolates of GLRaV-3 whose genome sequences are available in GenBank. Isolate ON8415A has up to $76 \%$ nucleotide sequence identities to other isolates representing existing variant groups. We also revealed high degrees of variation in both length and sequence in the terminal untranslated regions (UTRs) of GLRaV-3 variants. The 5'-UTR of most GLRaV-3 isolates whose complete genomes have been sequenced contain tandem repeats of 65 nucleotides, a highly unusual feature rarely observed in (+)single-stranded RNA viruses. Mechanisms for the biogenesis of these tandem repeats and their function in virus replication and pathogenesis require investigation. Findings of this research add to the genetic diversity, evolutionary biology, and diagnostics of GLRaV3 that afflicts the global grape wine industry.
\end{abstract}

The grape and wine industries constitute an important cornerstone of the economy of many countries. Diseases caused by viral pathogens are a major impeding factor for grape and wine production, as a result of a reduction in yield, quality of grapes, and wine products and the productive lifespan of vineyards (Mannini and Digiaro 2017; Martelli 2017). Grapevine is host to a large number of evolutionary diverse viruses (Dolja et al. 2017). More than 80 distinct viral species that belong to 29 genera and 17 families have been identified to date (Martelli 2018). The greatest economic impact is caused by viruses involved in three major disease complexes: infectious degeneration and decline, grapevine leafroll disease (GLD), and rugose wood (RW) disease complex. More recently, two new diseases have been recognized: grapevine red blotch caused by Grapevine red blotch virus (GRBV) (Cieniewicz et al. 2017) and grapevine leaf mottling and deformation with Grapevine Pinot gris virus as the putative causal agent (Saldarelli et al. 2017).

Infectious degeneration and decline are caused by infection with multiple viruses from the genus Nepovirus (family Secoviridae), which are transmitted by nematodes (Digiaro et al. 2017; Rowhani

${ }^{\dagger}$ Corresponding author: B. Meng; bmeng@uoguelph.ca

Funding: This research project was supported by research grants from the Natural Sciences and Engineering Research Council of Canada Engage Grant Program (project EGP469921) and the Discovery Grant Program (project RGPIN-2014-05306).

*The $\boldsymbol{e}$-Xtra logo stands for "electronic extra" and indicates that one supplementary figure and two supplementary tables are published online.

The author(s) declare no conflict of interest.

Accepted for publication 2 November 2018.

(C) 2019 The American Phytopathological Society et al. 2017). Diseases of the RW complex are putatively caused by several viruses of the family Betaflexiviridae, which include Grapevine virus A (GVA), Grapevine virus B (GVB), and other related viruses of the genus Vitivirus (Minafra et al. 2017) and Grapevine rupestris stem pitting-associated virus (GRSPaV) of the genus Foveavirus (Meng and Rowhani 2017). The GLD complex is associated with several viruses that belong to three genera of the family Closteroviridae. Grapevine leafroll-associated virus 1 (GLRaV-1) (Naidu, 2017), GLRaV-3 (Burger et al. 2017), and GLRaV-4 (Aboughanem-Sabanadzovic et al. 2017) are members of the genus Ampelovirus and are transmitted by multiple species of mealybugs (family Pseudococcidae) and scale insects (family Coccidae). GLRaV-2 is a member of the genus Closterovirus (Angelini et al. 2017), whereas GLRaV-7 is a member of the genus Velarivirus (Al Rwahnih et al. 2017). These two latter viruses are not known to be vector transmissible; in agricultural settings, they are transmitted through vegetative propagating materials and by grafting (Martelli et al. 2012; Naidu et al. 2014).

GLD is economically the most important viral disease of grapevine and GLRaV-3 is considered the predominant etiological agent of the disease (Burger et al. 2017; Maree et al. 2013). Earlier research revealed the existence of broad genetic diversity of GLRaV-3 (Bester et al. 2012; Chooi et al. 2013; Fei et al. 2013; Jooste et al. 2010; Maree et al. 2015). Through phylogenomic analysis of 13 available whole genomes and partial sequences, Maree et al. (2015) proposed the grouping of all GLRaV-3 isolates into seven variant groups, which were named by Roman numerals as groups I through VII. Complete genome sequences are available for viral isolates from groups I to III, VI, and VII. For variant group IV, only the $3^{\prime}$-terminal 4.6-kb sequences (corresponding to open reading frames [ORFs] 6 to 12) are available (Wang et al. 2011). For variant group $\mathrm{V}$ isolates, only the genomic region encoding the viral capsid protein (CP) was sequenced (Engel et al. 2008). These seven variant groups are further divided into three supergroups, designated as supergroups A through $\mathrm{C}$ (Maree et al. 2015). Supergroup A is the largest and comprises groups I to V. 
Supergroup B contains a single variant group (group VI) represented by three isolates (GH11, GH30, and CA7246) and two isolates from New Zealand (NZ-1 and NZ-1B) for which only the CP region has been sequenced (Chooi et al. 2013). Finally, supergroup C contains a single isolate (GH24), which was the only completely sequenced isolate at the time (Maree et al. 2015).

Major differences were observed among the different groups of viral variants. For instance, the small ORF2 is detected in isolates from groups I to $\mathrm{V}$ but is absent in isolates from groups VI and VII. In addition, the last two ORFs at the $3^{\prime}$-terminal region of the genome, ORF11 and ORF12, exhibit unusual levels of variability. This is especially the case for ORF11, as it is confidently predicted only in isolates of groups I to III. These observations raise the question of whether ORF11, and even ORF12, actually encodes a protein product (Maree et al. 2015). In light of the broad range of genetic diversities that have already been observed among GLRaV3 isolates for which the genomes have been sequenced, it is likely that additional and genetically divergent viral variants of the virus still exist in nature that await to be identified.

First established in the 1970s, the Canadian grape and wine industry is relatively new. With the creation of the North American Free Trade Agreement, the Canadian grape industry has gone through major changes, with large proportions of Vitis labrusca and French-American hybrid wine cultivars being replaced by $V$. vinifera wine grapes. Ontario has remained the predominant producer of grape and wine, followed by British Columbia, Nova Scotia, and Quebec. However, the situation of grapevine viruses, viral diseases, and their economic impact on grape and wine production in Canada has remained largely unknown. An earlier survey for the distribution of a small number of viruses was conducted in the 1990s (MacKenzie et al. 1996), which revealed the presence of two viruses associated with GLD (GLRaV-1 and GLRaV-3) and two viruses involved in infectious degeneration (Grapevine fanleaf virus and Arabis mosaic virus). This situation changed drastically in recent years as a result of outbreaks of diseases indicative of viral infections in many vineyards. Since 2013, the negative effects of viruses and viral diseases on the health, productivity, and sustainability of the grape and wine industry in Canada started to be keenly recognized by various stakeholders, including growers, wineries, government agencies, and the research community. In order to understand the distribution and prevalence of viruses and their impact on the grape and wine industry, we have conducted province-wide surveys for major viruses. Fourteen viruses were detected in commercial vineyards, with GLRaV-3, GRBV, GPGV, and GRSPaV being the most prevalent (Xiao et al. 2018). Two recent surveys were conducted in British Columbia on the distribution and genetic diversity of GRBV and four viruses associated with GLD (Poojari et al. 2017a, 2017b).

During sample collection and visitations to various vineyards, we have witnessed, first hand, severe losses and even total crop failure in numerous vineyards. One of the most affected sites was an organic cultivar Riesling vineyard block located in the Niagara Peninsula. This vineyard was established in the early 1980s. The owner of this vineyard had been experiencing substantial economic losses owing to a pronounced reduction in both the yield and quality of grapes. At the grower's request, we visited this vineyard in late fall of 2014. The Riesling vines exhibited severe decline, stunted growth, and only a few clusters of grapes contrary to what would be expected of a normal vineyard of this age. We also observed yellowing and downward rolling of leaves, typical of GLD.

To identify the viruses associated with this declining vineyard block, we performed a global analysis of the virome in a grapevine representing this vineyard block using the Illumina HiSeq 2500 platform and total RNAs. Five species of viruses and three viroids were identified. These included two viruses involved in GLD, as expected based on the disease symptoms, and three viruses that are associated with the RW disease complex. Furthermore, multiple genetic variants were detected for three of these viruses. Importantly, two of the sequenced GLRaV-3 variants were only distantly related to previously characterized variants of this virus.

\section{Materials and Methods}

Plant materials. Dormant cuttings were collected from a vine of the diseased Riesling in November 2014 from an organic vineyard in Niagara, Southern Ontario, Canada. We designated this vine as ON8415.

Isolation of total RNAs. Total RNAs were isolated from phloem scrapings of cuttings by using our modified method based on the Spectrum Plant Total RNA Kit (Sigma) (Xiao et al. 2015). The quality and concentration of the RNA preparations was assessed with a NanoDrop spectrophotometer (ND-1000; Thermo Scientific) at wavelengths of 230,260, and $280 \mathrm{~nm}$. The nucleic acid preparations were also evaluated with microfluidic electrophoresis chips using the BioAnalyzer system (Agilent Technologies).

High-throughput sequencing. The total RNAs were subjected to the removal of ribosomal RNAs (rRNAs) and the rRNA-depleted RNA samples were used for preparation of a cDNA library using the Illumina TruSeq RNA Sample Prep Kit. Sequencing was carried out on an Illumina HiSeq 2500 sequencer generating 51-bp singleend reads at the Donnelly Sequencing Centre, University of Toronto. The high-throughput sequencing (HTS) data set was first analyzed in the iPlant Discovery Environment. Initially, sequence reads from the cDNA library were mapped to the reference genome of $V$. vinifera (PRJEA18785) using TOPHAT2-SE to enrich the sequence reads related to viruses and viroids. Sequence reads not mapped to the grapevine reference genome were mapped using the Basic Local Alignment Search Tool (BLAST)-Like Alignment Tool available in iPlant to reference sequences corresponding to viruses and viroids. These nongrape sequence reads were also subjected to de novo assembly into contigs using CLC Genomics Workbench (Qiagen). Resulting contigs were subsequently used as queries to identify matching sequences using BLAST against complete reference sequences of viruses and viroids (http://www. ncbi.nlm.nih.gov/genome/viruses/) to identify viruses and viroids that were present in the sample. To obtain the complete or partial genome sequences of the viruses and viral variants detected, de novo assembled viral contigs were compared manually with individual viral genome sequences available in GenBank, which resulted in the assembly of draft genomes of various variants. Reference sequences used for comparison and for the identification of viral variants are provided in Table 1.

Confirmation of novel GLRaV-3 variants by reverse transcription polymerase chain reaction and Sanger sequencing. Near full-length genome sequences of two new variants of GLRaV-3, designated as ON8415A and ON8415B, were assembled using sequence data from HTS. For the purpose of verification of the draft genome sequences, primers were designed to amplify regions of each new variant that displayed significant deviations compared with other isolates that have been published Supplementary Table S1. Reverse transcription polymerase chain reaction (RT-PCR) was performed as described previously (Xiao et al. 2015) using primers designed based on the draft genome sequence of each novel isolate. Resulting PCR products were analyzed on 1\% agarose gel and amplicons of expected sizes were cloned into pGEM-T Easy Vector (Promega). Resulting positive clones were sequenced with M13 forward and reverse primers using an ABI 3730 capillary sequencer at the Genomics Facility of the Advanced Analysis Centre, University of Guelph.

Determination of the $5^{\prime}$ and $3^{\prime}$ termini of the genome of new isolates. The FirstChoice RNA ligase mediated (RLM)-RACE Kit (Thermo Fisher Scientific) was used to determine the $5^{\prime}$ and $3^{\prime}$ termini of the genome of isolates ON8415A and ON8415B. Two reverse primers (shared by ON8415A and ON8415B) and one forward primer for each isolate were designed for $5^{\prime}$ RLM-RACE, whereas two forward primers for each isolate and one reverse primer (shared by both isolates) were designed for 3'-RACE. Because the genome of GLRaV-3 lacks a poly(A) tail, poly(A)-tailing was first performed on total RNAs isolated from the infected vine with yeast poly(A) polymerase (USB). The 5' - and 3'-RACE was performed following the vendor's instructions. To further verify the $5^{\prime}$-terminal nucleotide of the genomes of these two new isolates, an independent 
RACE was conducted. Briefly, cDNA was prepared with specific primer $8415 \mathrm{AB}-5$ outR plus random primers using the HighCapacity cDNA Reverse Transcription Kit (Life Technologies). Poly(C)-tailing of the resulting cDNA was done using terminal deoxynucleotidyl transferase (New England BioLabs). This was followed by PCR amplification with primers $8415 \mathrm{AB}-5$ outR and dG-14 for the first-round PCR and $8415 \mathrm{AB}-5 \mathrm{inR}$ and dG-14 for the nested PCR. The resulting RT-PCR products were analyzed through electrophoresis on $1 \%$ agarose gel and the amplicons of expected sizes were cloned into pGEM-T Easy Vector as described earlier. Positive clones were first screened by colony PCR with virus-specific primers, followed by plasmid isolation and sequencing with M13 forward and reverse primers.

Phylogenetic analyses. Multiple sequence alignments and phylogenetic analyses were performed by using MEGA7 available online. The percentage identity and the phylogenetic tree were obtained through aligning the nucleotide or amino acid sequences using ClustalW. Isolates of GLRaV-3 used in the phylogenetic analyses were as follows: 623 (GQ352632), GH24 (KM058745), Cl-766 (EU344893), GP18 (EU259806), WA-MR (GU983863), PL-20 (GQ352633), 621 (GQ352631), NY1 (AF037268), LN (JQ423939), CA7246 (JQ796828), GH30 (JQ655296), GH11 (JQ655295), TRAJ-BR (KX756669), TC-BR (KX756668), ISAB-BR (KX701860), 3138-07 (JX559645), an isolate from Israel (KJ174518), and genome sequences of several other isolates that became available in GenBank, which includePro95 (KY707824), Trc138 (KY764333), Trc139 (KY764332), Rod96 (KY707825), NdA121 (KY707826) (Maher et al., unpublished data), and ID45 (MH796136; Thompson et al. 2019). GLRaV-1 isolate WA-CH (KU674796) was included as an outgroup. For further phylogenetic analyses of UTRs and select ORFs, only a subset of isolates representing genetic variant groups was included. Several isolates were excluded from further phylogenetic analyses either because these isolates were not completely sequenced (isolates $\mathrm{Cl}-$ 766 and NY1) or unverified sequences are available (isolate 139).

\section{Results}

A single vine contains multiple viruses and viral variants. Deep sequencing was used to identify the viruses and viroids in a Riesling vine exhibiting leafroll and general decline symptoms. Total RNA was isolated from cane phloem tissue and used for generation of a cDNA library, followed by single-end sequencing on the HiSeq 2500 platform. A total of 73,385,886 sequence reads were obtained from a ribo-depleted cDNA library derived from the sample designated ON8415 Supplementary Table S2. Among them, 23,026,032 reads were not mapped to the $V$. vinifera genome. These reads were mapped against the GenBank database of viruses and viroids (http:// www.ncbi.nlm.nih.gov/genome/viruses/). A total of 5,930,512 reads $(25.8 \%)$ matched sequences of the following five viruses and three viroids: GLRaV-1, GLRaV-3, GRSPaV, GVA, GVB, Grapevine yellow speckle viroid 1 (GYSVd1), GYSVd2, and Hop stunt viroid. The total number of virus and viroid reads accounted for $8.08 \%$ of the total sequence reads, indicative of significant levels of virus and viroid accumulation in this Riesling vine. By far, the most abundant virus was GLRaV-3 (84.93\%), followed by GVB (11.49\%) (Fig. 1).

Resulting contigs were investigated using BLAST against complete reference sequences of viruses, followed by manual comparisons with known genome sequences of the respective viruses and by assembly into draft genomes of individual virus variants (Table 1). Near complete genome sequences of three distinct variants of GLRaV-3 were assembled from the sequence reads derived from this sample (Table 1). Contigs 5, 8, and 12 were assembled into the draft genome of the first variant, which had $99 \%$ sequence identity and $96.6 \%$ genome coverage with isolate 623 (GQ352632; Jooste et al. 2010); the second was assembled from contigs 7 and 86 and consisted of 18,320 nt. Designated ON8415A, this draft genome had low nucleotide sequence identity of $76.2 \%$ to $\mathrm{GH} 24$ (KM058745; Maree et al. 2015), with a $99.1 \%$ genome coverage.

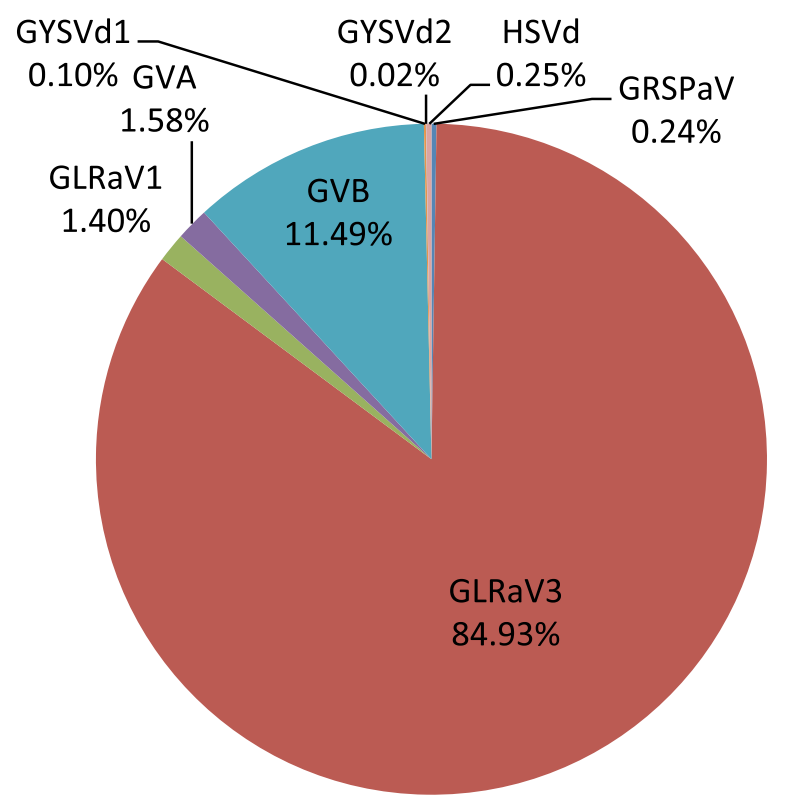

Fig. 1. Distribution of viruses and viroids identified in the CDNA library derived from sample ON8415. The abundance of sequence reads for the viruses is expressed as the percentage of sequence reads for each virus or viroid over the total number of virus/viroid reads. GYSVd = Grapevine yellow speckle viroid, HSVd $=$ Hop stunt viroid, GRSPaV = Grapevine rupestris stem pitting-associated virus, GLRaV = Grapevine leafroll-associated virus, GVA $=$ Grapevine virus $A$, and GVB $=$ Grapevine virus $B$.

Table 1. Summary of assembled sequence contigs from sample ON8415 and their mapping to viruses and viral variants ${ }^{\mathrm{a}}$

\begin{tabular}{|c|c|c|c|c|c|c|}
\hline Virus $^{b}$ & $\begin{array}{c}\text { GenBank } \\
\text { accession no. }\end{array}$ & $\begin{array}{l}\text { Reference } \\
\text { isolate }\end{array}$ & $\begin{array}{c}\text { Sequence } \\
\text { identity }(\%)\end{array}$ & $\begin{array}{l}\text { No. of } \\
\text { contigs }\end{array}$ & $\begin{array}{c}\text { Genome } \\
\text { coverage }(\%)\end{array}$ & $\begin{array}{c}\text { New isolates with full genome } \\
\text { sequence (GenBank accession no.) }\end{array}$ \\
\hline \multirow[t]{4}{*}{$\overline{\mathrm{GRSPaV}}$} & KT948710.1 & VF1 & $94-96$ & 4 & 97.3 & \\
\hline & HE591388.1 & SY & $96-97$ & 3 & 96.1 & \\
\hline & FR691076.1 & MG & 98 & 2 & 96.3 & \\
\hline & JQ922417.1 & GG & $97-98$ & 5 & 17.8 & \\
\hline \multirow[t]{3}{*}{ GVA } & КС 962564.1 & $\mathrm{I} 327-5$ & 83 & 5 & 96.1 & \\
\hline & DQ855084.2 & GTG11-1 & 82 & 9 & 77.9 & \\
\hline & JX559641.1 & $3138-03$ & 79 & 1 & 93.3 & \\
\hline GVB & X75448.1 & Italy & 97 & 1 & 100 & ON8415 (KY426923) \\
\hline GLRaV-1 & KU674796 & WA-CH & 99 & 2 & 99.9 & \\
\hline \multirow[t]{3}{*}{ GLRaV-3 } & GQ352632.1 & 623 & 99 & 3 & 96.6 & \\
\hline & KM058745.1 & GH24 & 76.2 & 2 & 99.1 & ON8415A (KY073323) \\
\hline & GQ352633 & PL20 & 67.1 & 3 & 99.3 & ON8415B (KY073324) \\
\hline
\end{tabular}

\footnotetext{
${ }^{a}$ De novo assembled viral sequence contigs from sequence reads derived from the cDNA library derived from sample ON8415 were manually compared with the known viral genome sequences followed by assembly into various virus variant sequences.

${ }^{\mathrm{b}} \mathrm{GRSPaV}=$ Grapevine rupestris stem pitting-associated virus, $\mathrm{GVA}=$ Grapevine virus $\mathrm{A}, \mathrm{GVB}=$ Grapevine virus $B$, and GLRaV $=$ Grapevine leafroll-asso-
} ciated virus. 
The third variant, which is designated here as ON8415B, was assembled from contigs 4,16 , and 22 , consisted of $18,373 \mathrm{nt}$, and had only $67.1 \%$ sequence identity on average compared with isolate PL-20 (Jooste et al. 2010), with a $99.3 \%$ genome coverage (Table 1).

In addition, three new and divergent variants of GVA were also detected. Variant 1 had 83\% sequence identity with I327-5 (KC962564; Goszczynski 2014); variant 2 was $82 \%$ identical to isolate GTG11-1 (DQ855084; Goszczynski 2007); and variant 3 had $79 \%$ identity to isolate 3138-03 (JX559641; Rott and Belton, unpublished data). In contrast, only a single variant of GVB was detected. The complete genome of GVB was assembled from sequence reads from this sample (GenBank accession no. KY426923), which had 97\% sequence identity with X75448.1 from Italy (Saldarelli et al. 1996) (Table 1). Furthermore, four variants of GRSPaV as well as a single GLRaV-1 variant were also detected (Table 1).

Completion of genome sequences of two new and divergent GLRaV-3 isolates. Based on assembly of sequence reads derived from HTS, the draft genome sequences for both ON8415A $(18,250$ nt) and ON8415B (18,373 nt) were obtained. Alignment with the complete genome of isolate $\mathrm{GH} 24$ suggested that both draft genome sequences were incomplete at each end of the genome, which also exhibited apparent deletions and insertions in both terminal regions as well as regions of low confidence in sequence quality throughout the genome. Therefore, we set out to complete and validate the draft genome sequences of these two new GLRaV-3 isolates.

To obtain the sequence corresponding to the $5^{\prime}$ termini of ON8415A and ON8415B, we performed RACE using two independent RACE approaches. First, we used the RLM-RACE system (Thermo Fisher Scientific) and two reverse primers conserved for both variants together with a primer targeting the RNA adaptor provided in the commercial kit. After RT-PCR and cloning, six clones were obtained, two of which (310-A1 and 310-A2) were specific for ON8415A and four for ON8415B (310-A4, 310-A5, 310-A7, and 310-A8). The ON8415A-related clones were nearly identical to each other and extended the genome sequence by $220 \mathrm{nt}$ beyond the initial draft genome. It is important to note that the draft genome sequence was missing $70 \mathrm{nt}$ (nucleotide positions 572 to 641 based on the final complete genome). Among the four ON8415B-related clones, three had apparently nonviral sequences beyond the matching region. BLAST searches demonstrated that these sequences were derived from the cytochrome $\mathrm{P} 450$ gene of grapevine. The remaining clone $310 \mathrm{~A}-7$ matched the 5 -terminal sequence of the draft genome and extended it by $28 \mathrm{nt}$.

Because the available RLM-RACE kit did not allow us to distinguish whether the very 5'-terminal nucleotide of the genome is a single or double "A," we used the terminal deoxynucleotidyl transferase for C-tailing of the first-strand cDNA, followed by PCR with oligo (dG) primer and virus-specific reverse primers. This RACE approach allowed us to confidently identify " $\mathrm{A}$ " as the 5 '-terminal nucleotide for both ON8415A and ON8415B.

To obtain the 3 -terminal sequence for each of the new GLRaV-3 variants, we performed A-tailing of total RNAs, followed by RTPCR with oligo(dT) primer and virus-specific forward primers and cloning of the resulting products. This approach allowed us to extend the draft genome sequences of ON8415A and ON8415B by 34 and $162 \mathrm{nt}$, respectively. It was determined that both genomes possessed a "C" as the last nucleotide, similar to most of the other known GLRaV-3 isolates available from GenBank (Fig. 2).

To confirm the sequences corresponding to the internal regions of uncertainty, we conducted RT-PCR using primers designed to flank each uncertain region, followed by cloning of PCR products into a TA vector and sequencing. Specifically, primer pair LR3-8415A8882F and LR3-8415A-10433R was used to amplify the genomic region containing the internal questionable region between nucleotide positions 9,200 and 10,450. As a result, two clones (289-A2 and 289A3) were selected for sequencing, with both clones being $99.8 \%$ identical and matching perfectly to the draft genome. A similar strategy was used to verify the uncertain regions in the draft genome of ON8415B. Specifically, we designed a second pair of primers (LR3-8415B-16223F and LR3-8415B-17153R) and used them in
RT-PCR to amplify the region of uncertainty located at nucleotide positions 16,252 to 17,153 . As a result, we obtained and sequenced two clones: 249-B2 and 249-B3. Sequences of both clones were 99.6\% identical to each other and had a nearly perfect match to the draft genome. Similarly, to verify the uncertain region located between nucleotide positions 4,200 and 5,700, primers LR3-RLB4196F and LR3-RLB5703R were designed and used in RT-PCR, and the amplification products were cloned. Because both clones had inserts of similar size based on restriction digestion, we sequenced one of them (T-PCR-C4). The sequence of this clone was identical to the draft genome sequence except for a single mismatch.

Upon compilation of the sequences derived from HTS, from the $5^{\prime}$ and $3^{\prime}$-RACE, and from RT-PCR targeting internal regions, the complete genome sequences for both ON8415A and ON8415B were obtained. The genome of ON8415A (KY073323) is 18,573 nt in length, contains a 5'-UTR of $737 \mathrm{nt}$, a 3'-UTR of $303 \mathrm{nt}$, and 12 ORFs lacking ORF2. The genome of ON8415B (KY073324) is 18,564 nt long, with a shorter $5^{\prime}$-UTR of $672 \mathrm{nt}$, a longer 3'-UTR of $350 \mathrm{nt}$, and 13 ORFs including ORF2. Overall, the two isolates differ from each other by $33.1 \%$ in genome sequence.

ON8415B is a unique and highly divergent isolate of GLRaV3. At the time this work was being completed, seven phylogroups of GLRaV-3 variants had been recognized (Maree et al. 2015). These groups were further classified into three supergroups designated supergroup A (groups I to V), supergroup B (group VI), and supergroup $\mathrm{C}$ (group VII, GH24). For unknown reasons, the partial sequences from Portugal representing group VIII were removed from GenBank; hence, group VIII and supergroup D are obsolete. As this manuscript was being reviewed for publication, genome sequences of several isolates became available in GenBank, including five from California (Pro95 [KY707824], Trc138 [KY764333], Trc139 [KY764332], Rod96 [KY707825], and NdA121 [KY707826]) and one from Idaho (ID45 [MH796136]). Thompson et al. (2019) proposed group IX as a new group to contain four highly similar isolates: ID45, Pro95, Trc138, and Rod96.

The nucleotide sequence identities of isolate ON8415B to other GLRaV-3 genomes were very low and fell in the range of 66.8 to $72.4 \%$, which are much lower compared with identity values of $\sim 88$ to $91 \%$ between variants across groups I, II, III, and VI. Based on these results, we conclude that ON8415B is a highly divergent isolate that appears to be a sister variant more closely related to group IX (Fig. 3A). Similar to isolate PL-20 (group III), the 5'-UTR of ON8415B is 672 nt in length (Fig. 4), shorter than most other isolates. However, the sequence identity of the $5^{\prime}$-UTR between ON8415B and other isolates is very low, ranging from 45.8 to $56.1 \%$. In contrast, it has the longest $3^{\prime}$-UTR (350 nt) of any completely sequenced GLRaV-3 variants (Fig. 2). The sequence identities between the 3'-UTR of ON8415B and those of other variants range from 69.7 to $86.2 \%$ (Table 2). The identity levels for ORF1b, ORF4, and ORF6 of ON8415B relative to other variants are 75.6 to $77.6,72.9$ to 79.4 , and 75.0 to $82.0 \%$, respectively, in nucleotide sequence (Table 2); the corresponding amino acid identities are 87.2 to $89.1,84.2$ to 90.9 , and 88.5 to $96.2 \%$ (Table 3). Considering the large divergence of this isolate compared with members of group IX, it seems reasonable to suggest that ON8415B may represent a new genetic variant group of GLRaV-3.

We also noted that ON8415B appeared to be more closely related to groups I to III than to groups VI, VII, and IX when the 5'-UTRs were compared. In contrast, it appears more closely related to groups VI and VII than to groups I to III when the other genomic regions were compared (data not shown). This incongruence over different regions of the genome is also reflected in the phylogenetic trees where ON8415B is positioned beside the clade of groups I to III for ORF1a (data not shown), ORF4 (SF1B), and ORF6 (Fig. 3B), whereas it is positioned between groups VI and VII in the tree for ORF1b (SF1A). This suggests that recombination events might have taken place between different viral variant groups in the past, leading to the emergence of isolate ON8415B.

ON8415A is distantly related to group VII variants of GLRaV3. Sequence analysis of multiple regions across the genome revealed 
that ON8415A differs significantly from all other known GLRaV-3 variants, with nucleotide sequence identities ranging from 66.8 to $76.2 \%$ (Table 4). Because only partial sequences are available for groups IV and V, further comparisons at the ORF level could be made only for the variant groups I to III, VI, and VII. We found that ON8415A was distinct from all five variant groups but more closely related to $\mathrm{GH} 24$ (with $76.2 \%$ sequence identity) and $\mathrm{NdA} 121$, both members of group VII (Fig. 3A; Table 4).
Similar to variants of groups VI (CA7246, GH11, and GH30) and VII (GH24), the ON8415A genome contains a 5'-UTR of $737 \mathrm{nt}$ and lacks ORF2. It was noted, however, that the sequence identities of the 5 '-UTR between ON8415A and other isolates are very low, ranging from $47.9 \%$ to the highest value of $60.6 \%$. Interestingly, the $3^{\prime}$-UTR of ON8415A (303 nt) is longer than all other variants except ON8415B (Fig. 2), with 73.6 to $90 \%$ sequence identities compared with other variants (Table 4). The genome regions of ON8415A
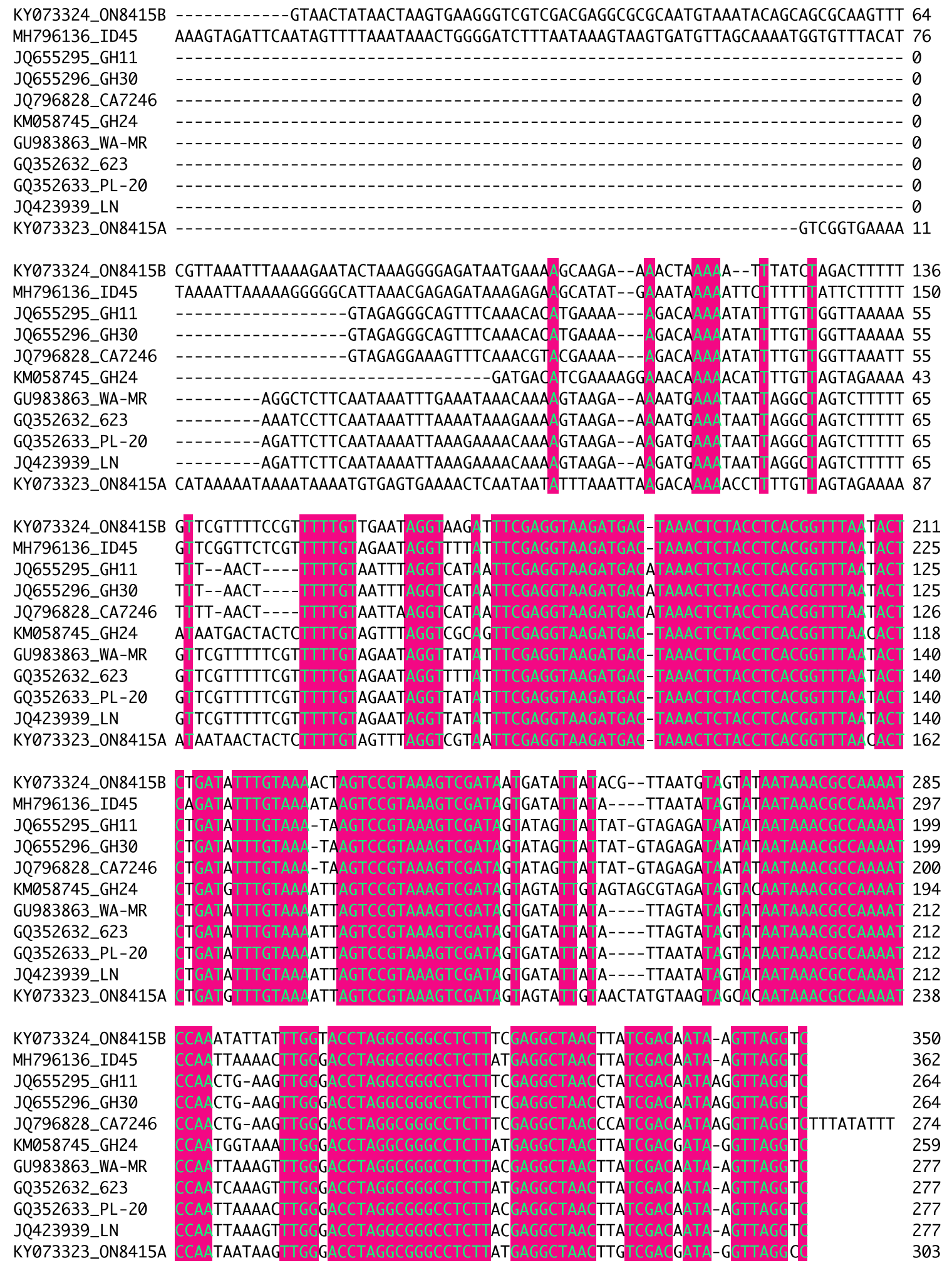

Fig. 2. Multiple alignment of $3^{\prime}$-untranslated regions (UTRs) of representative isolates for which the complete genome sequences are available. The GenBank accession number, isolate name, and nucleotide position are provided for each of the isolates. Note that the beginning one-third of the $3^{\prime}$-UTR is highly variable, whereas the remaining two-thirds of the $3^{\prime}$-UTR are more conserved among different isolates. The last nine extra nucleotides present in isolate CA7246 are likely nonviral. 
encoding RdRP (ORF1b), Hsp70h (ORF4), and major capsid protein (ORF6) were 76.6 to $84.4,72.8$ to 79.6 , and 74.8 to $82.7 \%$ identical compared with other GLRaV-3 isolates, respectively (corresponding amino acid identities were 88.2 to $93.7,82.7$ to 88.9 , and 89.8 to $96.2 \%$ ) (Tables 4 and 5). Sequence differences between ON8415A and other variant groups were even greater when the remaining nine ORFs were compared, which are generally less conserved among members of the family Closteroviridae (Tables 4 and 5) (Dolja et al. 2006). The nucleotide sequence identities of variants among groups I, II, and III are greater than $87.6 \%$ in these three ORFs, which is considerably higher than that between ON8415A and groups I to III (with the highest identity value of $82.7 \%$, see above). Furthermore, the identities of members of the highly variable group VI are greater than $90.8 \%$.

The 5'-UTRs of GLRaV-3 variants including ON8415A and ON8415B are highly variable and contain tandem repeats. The 5 '-UTR of GLRaV-3 exhibits unusual features that are not observed in other viruses outside the genus Ampelovirus. First, the 5'-UTRs of GLRaV-3 isolates are unusually long and vary in length considerably among the different variants, ranging from 642 nt (for GH30) (Bester et al. 2012) to $802 \mathrm{nt}$ (for LN) (Fei et al. 2013). Isolates ON8415B and PL-20 both have a 5'-UTR of $672 \mathrm{nt}$ (Fig. 4). Second, all of the variants for which complete genomes have been sequenced thus far contain tandem repeats of $65 \mathrm{nt}$ in the 5'-UTR, albeit the levels of sequence identity between these repeats vary from virus to virus. In addition, the copy numbers of repeats also vary, ranging from 2 to 4 (Fig. 5). It is interesting that the new isolate ON8415A contains four copies of repeats with sequence identities of 69.2 to $83.1 \%$ between them (Fig. 5). Third, the 5'-UTRs of different variants exhibit
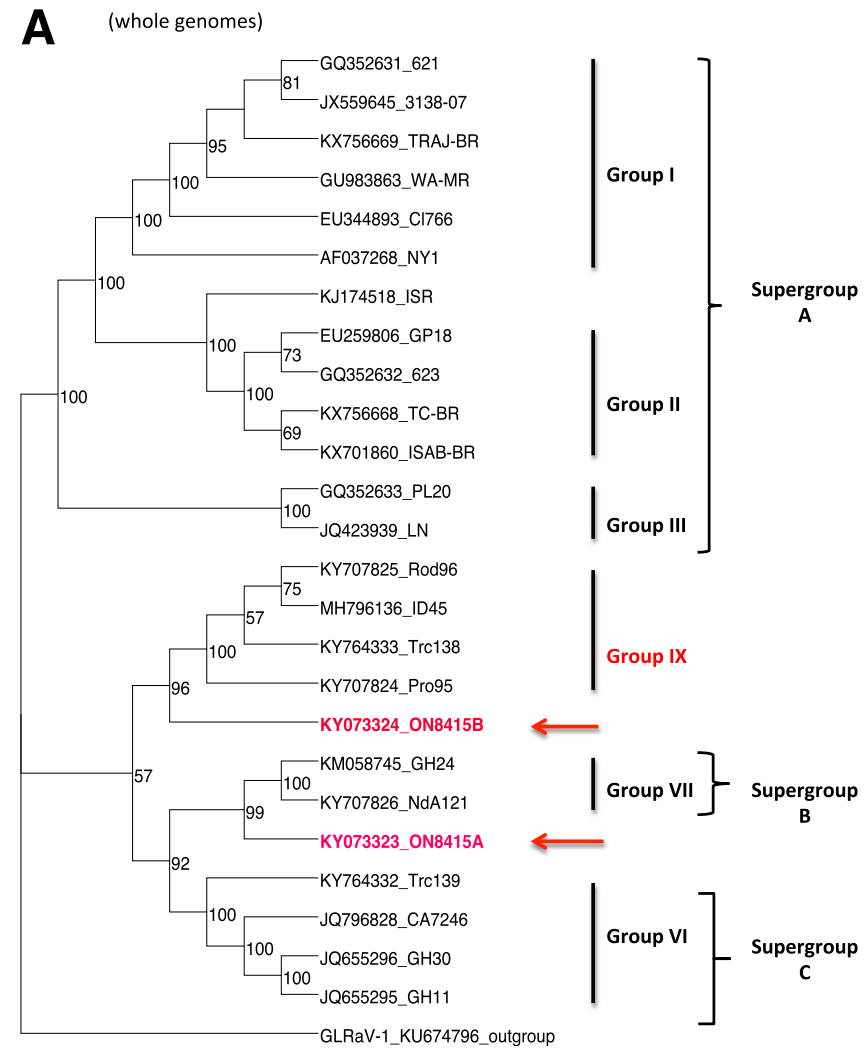

(Continued)

Fig. 3. Phylogenetic analyses of Grapevine leafroll-associated virus 3 (GLRaV-3) isolates representing sequence variant groups. Phylogenetic trees were generated based on $\mathbf{A}$, complete or near complete genomes and $\mathbf{B}$, open reading frame 6 (ORF6). One representative isolate from each variant group was used for the construction of phylogenetic trees. The GenBank accession number and name are provided for each isolate. Grouping of isolates into viral variant groups and supergroups is also provided. Phylogenetic trees shown were generated using the maximum likelihood method with 1,000 replications of bootstrapping. Trees with similar topology were obtained using the Neighbor Joining method. extensive sequence variation. For example, the $5^{\prime}$-UTR of isolate ON8415A shares sequence identities from 47.9 (to PL-20) to $60.6 \%$ (to ID45). Similarly, the $5^{\prime}$-UTR of isolate ON8415B has the lowest identity of $45.8 \%$ (with PL-20) to the highest $56.1 \%$ (with ID45) (Table 2). It is worth noting that in spite of these variations in both sequence and length of the $5^{\prime}$-UTRs, the first 40 nt of all completely sequenced genomes are nearly invariable, suggesting critical functions of this sequence segment in viral genome replication (Fig. 4).

The 3'-UTRs of GLRaV-3 isolates vary in length and nucleotide sequence. Similar to the $5^{\prime}$-UTRs, a high degree of variability is observed in the $3^{\prime}$-UTRs of different GLRaV-3 variants. Their size ranges from $259 \mathrm{nt}$ for GH24 to $350 \mathrm{nt}$ for ON8415B, with those from groups I to III all being 277 nt (Fig. 2). The 3'-UTR of ON8415A is $303 \mathrm{nt}$ in length. Second, they also exhibit differences in sequence, with identities ranging from 69.7 to more than $90 \%$ among variants. The identities between the 3'-UTR of ON8415A and those of other variants range from 69.7 (with ON8415B) to $90 \%$ (with GH24). The identities between the $3^{\prime}$-UTR of ON8415B and those from other variants range from the lowest $69.7 \%$ (with ON8415A) to the highest $86.2 \%$ (with WA-MR). A majority of these differences are located in the $5^{\prime}$-proximal one-third of the 3'-UTR. In contrast, the 3'-proximal two-thirds of the 3'-UTR of GLRaV-3 isolates are more conserved and contain several invariable stretches of sequences ranging in size from 16 to $22 \mathrm{nt}$ (Fig. 2).

\section{Discussion}

In this study, we further demonstrate the utility of HTS for the global and unbiased identification of viruses from crop plants. This technology is especially attractive for the asexually propagated, perennial woody plants such as grapevine (Al Rwahnih et al. 2009, 2012a, 2012b; Coetzee et al. 2010; Fajardo et al. 2017; Giampetruzzi et al. 2012; Glasa et al. 2014, 2017; Maliogka et al. 2015; Poojari et al. 2013; Zhang et al. 2011). Together with other recent HTS studies (Al Rwahnih et al. 2009; Coetzee et al. 2010; Pantaleo et al. 2010; Zhang et al. 2011), our work revealed a highly complex nature of

Fig. 3. (Continued)

$B(\mathrm{ORF} 6, \mathrm{CP})$

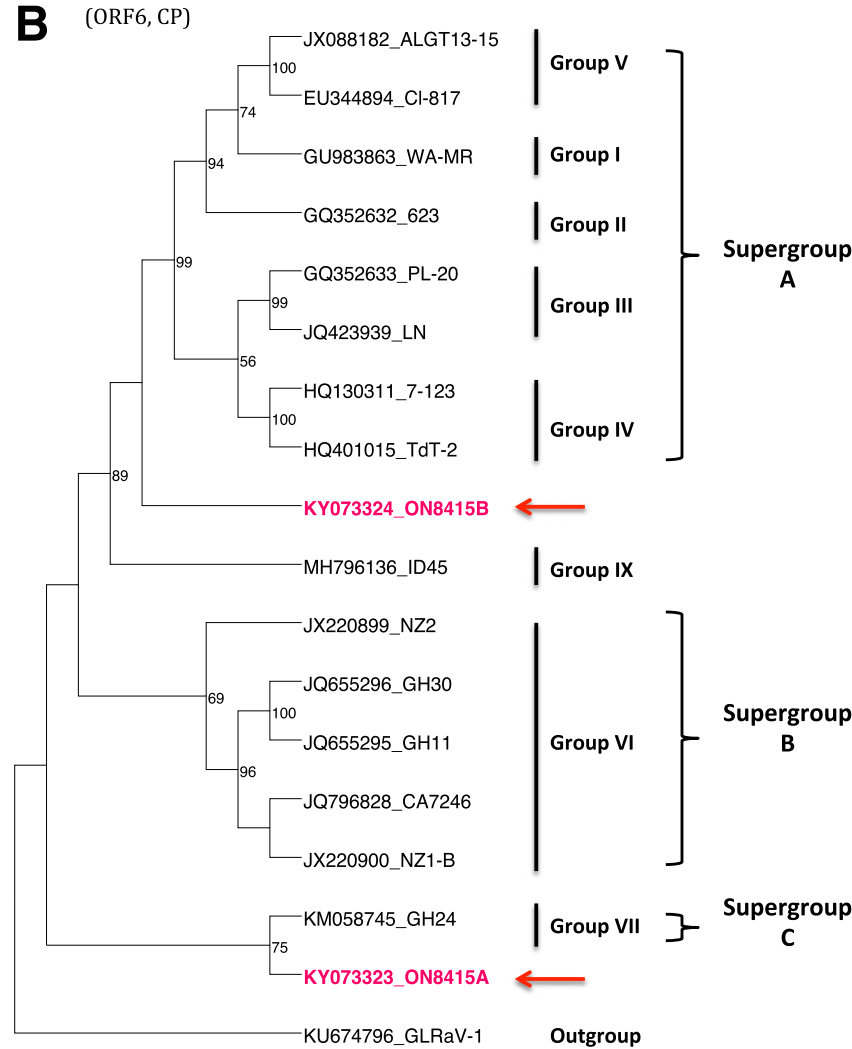


viral infections in grapevine. Three types of nucleic acids have been used as templates in HTS for the identification of grapevine viruses, which include double-stranded RNA (Al Rwahnih et al. 2009, 2012b, 2013; Coetzee et al. 2010), small RNA (Fajardo et al. 2017; Giampetruzzi et al. 2012; Glasa et al. 2014; Maliogka et al. 2015; Navarro et al. 2009; Pantaleo et al. 2010; Velasco et al. 2014; Zhang et al. 2011), and total RNAs (Al Rwahnih et al. 2009; Beuve et al. 2015; Glasa et al. 2017; Jo et al. 2015). In this study, we have demonstrated that total RNAs are as effective, and perhaps even better, for the global identification and genome assembly of viruses, including both RNA viruses (this study) and DNA virus (our unpublished data). We predict that total RNAs will become the method of choice in future studies for the identification and genome sequencing of viruses in grapevine and other plant species.

One of the most important outcomes of this study is the discovery and sequencing of the complete genomes of two new and highly

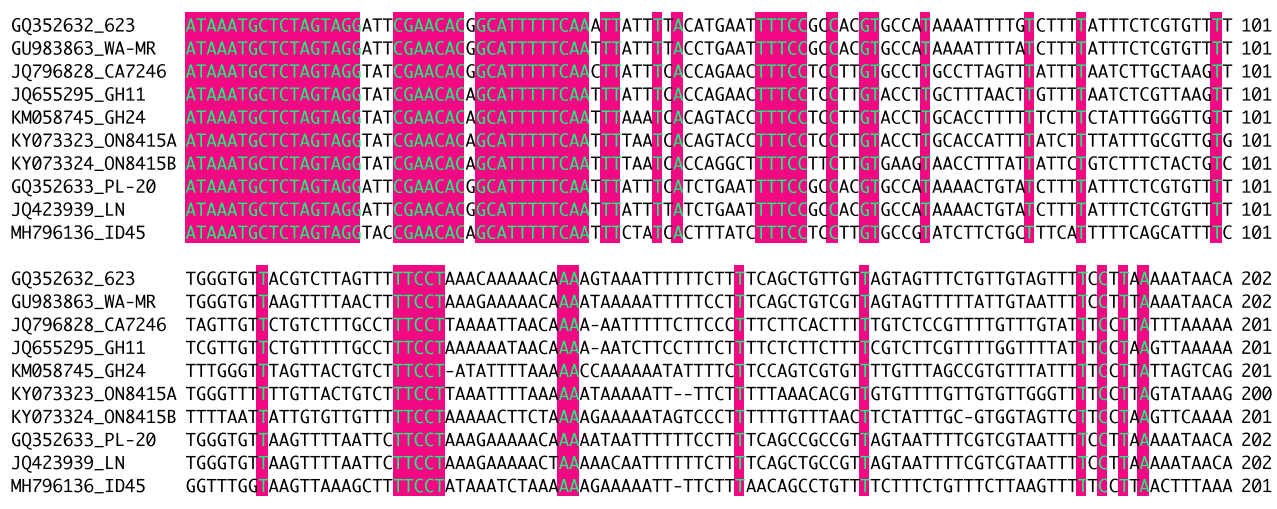

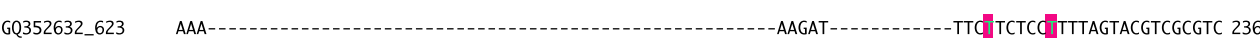
GU983863_WA-MR AAATTTTTCTTTTCTCTTATTGGGGT--TTCGTGTTTTGTAGTCATTAACTTTCCTTTAAAATAACAAAATTTTTCTC ITCTCT TTTGGTGTTTCGTGTT 301 JQ796828_CA7246 GAAAAATATAAGTTCCCCTTTTCTTTTTCTTTTGT-GCGTAGTGTTGGGTTTTCCTTTAAGTAGTAGGAAGTCATTTCIITCTTCITTTGCTCTTTTCTTGC 301 JQ655295_GH11 GAAAAATATAAGTTCTCTTTTTCTTTTTCTTTTGT-GCGTAGTGTTGGGCTTTCCTAATTTGAAAAGATAAATATAAG ITCTTI ITTCTTTTTCTTTTGT 301 KM058745_GH24 AAAAACAAAAAATTTTTCTTCCTT-TGTGTGGAGTAGCGTCGTGTTAAGTTTTCCTTCAAGTAAGTATAGTGTGTTTT GGGTTITTATTTTTCGTACGTA 301 KY073323_0N8415A AAAAGAAAAATTTTCTCCTTTTCT-TTTGTTGTGTGGTGTCGTTTTGGGTTTTCCTTAATATAGTAAAAAAAGAAATT ICTTTTCTTCTTTTGTTGTGTG 300 KY 073324 ON8415B ATCAAAAAATTATTCTTCTTTTTAGTCGTTTTTGTTTTGTCTAGTTAG-CTTTCCTAAGAAAAGAAAAAACAAAAATAIITCTTCITTTGGTTTAGATTGTG 301 GQ352633 PL-20 AAAATTTTTCTTTCTTTTTCACCCGCCGTTAGTAATTT-TCGTCGT-AATTTTCCTTAAAAATAACAAAATTTTTCT TCTCT TCCAGTGTTCGTGTT 301

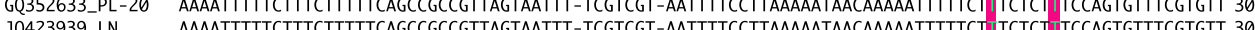
$\begin{array}{ll}\text { JQ423939_LN } & \text { AAAATTTTTCTTTCTTTTTCAGCCGCCGTTAGTAATTT-TCGTCGT-AATTTTCCTTAAAAATAACAAAAATTTTTCT ITCTCT TCCAGTGTTTCGTGTT } 301 \\ \text { MH796136_ID45 } & \text { AGAAAAAGAATTTTCTTTTCTAGC-TCGTCTTTGTCTTGTCTTTTAGGTTTTTCCTCAATTTAAAAATTTAAAAATTTITCTTTITAGTCCGTCTTTGTT } 301\end{array}$ GQ352632_623 TTGTCATCTTTAATTTTCCTTGCGTCTGTTTAGGTTTGCG CAAGTTTI CTTTGCGTCTTCGTGTTTTTAGTTTTAGTTTITCCTAAGTGTCTTTTAAGAG 337 GU983863_WA-MR TAGTAGTTATTAACTTTCCTAGAGTCTGTTTAGGTTCGTG ITTAGTTT CTCTGCGCTTCCGCGTCTTAAGTTTTAACTC TTCCTAAGCGTCTTTTAAGAG 402 JQ796828_CA7246 GCGTAGTGTTGGGTTTTCCTTTGAGTAGTAGTGAGTTATT CTTCTTC TTTGCACTTTTCTTGTTCGTGGCGTTAGGTT TTCCTAAAAATTTAAAATCAA 402 JQ655295_GH11 GCGTAGTGTCGGTCTTTCCTTTAAGTAGCAGTAAGTTCTC TCTTTTC TTTGCACTTTTCTTGTGTGTGGCGTTAGTTTITCC IAAAAATTAAAAATCAA 402 KMפ58745_GH24 TTTTCGTATTTAGTTTTCCTAGTTATAAGCATAGCGCGTT ICTATTT IGTTTTTTCGTGTTCTTCGTTTTTCCAGTTTITCCTAGTTCTAAGTGTGGTA 402 KY073323_0N8415A GTGTCGTTTTAGGCTTTCCTTTATTTAAGTAAAAGAAAAA TTTTTCT TATTTCTTGTTGTGTGGCGTCGTTTTAGGCT TTCCITTATAAAAGTGAAAA 401 KY073324_0N8415B TGTGTGTAACAGCA ITCCIGTTTTCGTCTCTAAGATAGA AGTCCTT ITATCTCTTAGTTGCGTCGTTGTTTTCGTTTITCCITTCTTTACTTGCGCGG 402 $\begin{array}{ll}\text { GQ352633_PL-20 } & \text { TCTTTGTTACAAAC TTTCCTAGAGTCTCTTTAGGTTTGAG CTAGTTT ITTAGTGTTTTCGTGTCTTTAGTTTTGGCCT TICC IAAGCGTTATTTAAGAG } 402 \\ \text { JQ423939_N } & \text { TCTTTGTACAAACTTTCCTAGAGTCTCTTTAGGTTGAG }\end{array}$

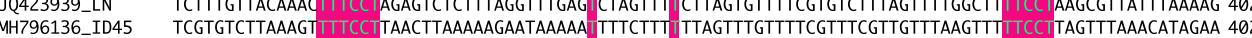

GQ352632_623 GGTTAGT CTCTTIATCG\| GTTGGGTAAATTTAGATT TAGAT TTCCTTTTACAAAGATAGACAACGTCGTTITCTTTTAG GCCTCG ITTCCGTTTCT 438 GU983863_WA-MR GGTTGG CTCAT GTCG GTTGGGTTAATTTAGTTT TAAAATTTCCCTTTTAAAAAAGAAAAAACGTCATTI TCTTTTAG GCTTTG ITTTCCGTTTTT 503 JQ796828_CA7246 AAATATT CTCCT TTGG TTAGTTTGATTTGTGTTGITAATC TICCCTTTTTTAAAATTTAAGTTAAAGT TITCTTTAAG GTCGG-IAGTGTT-CGTA 501

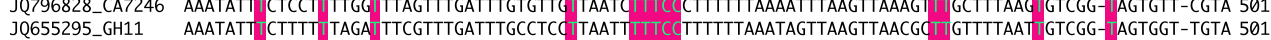

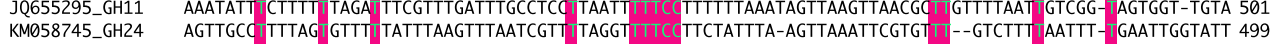

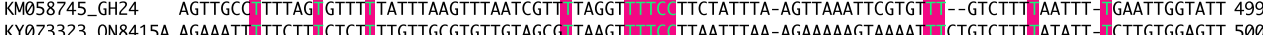
KY073323_0N8415A AGAAATT TTCTT CTCT TTGITGCGTGTTGTAGCGITAAGT TTCCTTAATTTAA-AGAAAAAGTAAAAT TITGTCTTT IATATT- CTTGTGGAGTT 500

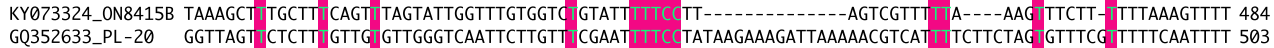
$\begin{array}{lll}\text { GQ352633_PL-20 } & \text { GGTTAGT CTCTT GTTG GTTGGGTCAATCTTGTT CGAAT TTCCTATAAGAAAGATTAAAAACGTCAT TITTCTAG ITTTCG ITTTCAATTTT } 503 \\ \text { J0423939_LN } & \text { GGTTAGT CTCTT GTTG GTTGGGTCAATTCTTGTT CGAAT ITCCTATAAGAAAGATTAAAAACGTCAT TCTTCTAG ITTTCG ITTTCAATTTT } 503\end{array}$ $\begin{array}{lll}\text { JQ423939_LN } & \text { GGTTAGT CTCTT GTTG GTTGGGTCAATTCTTGTT CGAAT TTCCTATAAGAAAGATTAAAAACGTCAT TCTTCTAG IGTTTCG ITTTCAATTTT } 503 \\ \text { MH796136_ID45 } & \text { GGTACCTITTCTTITGTITACGTTTGAAGCGTTCTTIAGTCITCCTCTCTTAAG-GGTTAAAAGGGTTTITCTTCAACITCAC-ITTGAAGTGTT } 501\end{array}$

GQ352632_623 TTGTAATTTTCCTTTGCGAATTIAAAAATTTTIIITTTTATTTCTTTIIAGTTGCGGCATTIIACTATTTTAATTTTCCTTTAGCGTTTTTGTGGTGGTTTTT 539

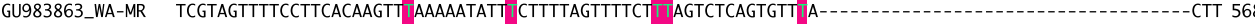
JQ796828_CA7246 GCACTGTCTTTTCCC---TTTT GTTG----- TAACAGAGTCCCCT T1--------TCITTTACCCAATTTTA---CTAGTGTTTTC-----TTCGT 574 JQ655295_GH11 GTGCCGTCTTTTCCT---AATT TAAG----- TACAGAGTCTACT I---------TCITTTATTTAATTTCA---TTAGTATTTTC------TTTGT 574 KM058745_GH24 G-GTAATATATCCTT---CCTTTTCT-----_ GA-AGATAACTTC TT----_----CT ITTCTCGTTTTTTCTTTTGTGGTGTTGGT-----AGTATTT 574 KY073323_0N8415A GCGTTGGGTTTTCCT---TAGT TAA------ IAACAGAGTAGTTT II---------GTITTTCTATAGTTATCCCTTT--TATTATT-----CGTACT- 574 KY073324_ON8415B TCAAA-----TTCC-----AGCIC--G---- TATTAGG--AACTT GQ352633_PL-20 TCAA-_LATTCCTTACGAAAT C--G---- ATTAGG--AACTT GQ352633_PL-20 TTGTAACTTTCCTTTACGAAATT AAAATTTTT CTTTCAGTTTTCT TIGTTGTAGCGTT ATTACTTTAACTTTCCTTTAGTGTTTTTGTGGTAGTTCTT 604 $\begin{array}{ll}\text { JQ423939_LN } & \text { TTGTAATTTCCTTTACGAAAT IAAAATTTTT CTTTCAGTTTTCT IAGTTGTAGCGTT ATTACTTTAACTTTCCTTTAGTGTTTTTGTGGTAGTTCTT } 604 \\ \text { MH796136_ID45 } & \text { TTGAAATCTTTTCCT---AAGTIAAAG---- }\end{array}$

GQ352632_623 CIITCTCIITGGTGTGTTTAGCGTGAGTGTTTTTCTATTTTCCTACGTACCATCTAGGGAGTCTTATCTAAGTTTTAACTTCTTTTCTTTTCTAGTTTTTAAT 640 GQ352632_623 CITCTCITGGTGTGTTTAGCGTGAGTGTTTTTTCTATTTTCCTACGTACCATCTAGGGAGTCTTATCTAAGTTTTAACTTCTTTTCTTTTCTAGTTTTTAAT 640

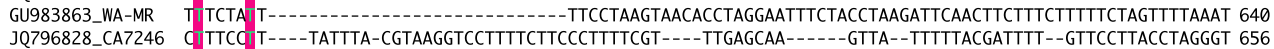
$\begin{array}{ll}\text { JQ796828_CA7246 } & \text { GITTCC T----TATTTA-CGTAAGGTCTTTTCTTCCCTTTTCGT----TTGAGCAA-------GTTA--TTTTTACGATTTT--GTTCCTTACCTAGGGT } 656 \\ \text { J0655295_GH11 } & \text { CITTCCIT----TCTTCA-CGTAGGGTCCTTTTCTTCCCCTTTCGT----TTGAGTAA------GTTG--CTCTAACGGAATT--GTTCCTTACCTAAGGT } 656\end{array}$ $\begin{array}{ll}\text { JQ655295_GH11 } & \text { CITTCQIT----TCTTCA-CGTAGGGTCCTTTTCTTCCCCTTTCGT----TTGAGTAA------GTTG--CTCTAACGGAATT--GTTCCTTACCTAAGGT } 656 \\ \text { KM958745_GH24 } & \text { CITTCCIT----TTCTTAAAGTCAGCACTTTCTCTTCTAACTTT-A----TTTAGG-G-----TCGTGTTTGTAAAACTTT--TTCCTTATTTTTTA-G } 656\end{array}$ KYø73323_ON8415A - ITTCCIT----TT--AAAGACTTTTAGTTAATCTATTAGTTTTGA----TTTAGAAG------TTGGGTTTCTAGTCTTCTT--TTCCTTTTATCGTAAG 656 KY073324_0N8415B TTICTTTI T----GTTTTGGGATTTTATCCGTTTCTTCTTACTTTCC----TTTGTTAA------C--GGTAGTTAAAGCT----GQ352633_PL-20 CITTTA TAGTGTGTTTAGTGTGT-1

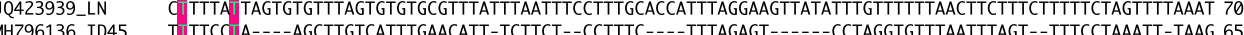

\begin{tabular}{|c|c|c|c|}
\hline & TTTCCTGCTGTTTGAGGGAAGTTTGTCCTTCTTCTTTAGTTCCCCCCTTTTTAATCCTTTT, & & \\
\hline 983863_WA-MR & GTTTGCCCTTCTTCTTCCGTCGTCCTTCGTAAACCATTATTTTCTA & ГССТСТCСTTTTAAG & ITTAAGTTTCGCT \\
\hline 96828_CA7246 & TTAAGC-TTAATT--------- TTTGTGT-TTAGTTATATACGTGGTTTAGTTCTTCCCC-- & CCTAAGTATTTTTC & ITTGTTCAAGGTC \\
\hline 555295_GH11 & TTAAGT-CTAATT---- & CCTAAGTACTTTTC & ITTACCTAAGGTC \\
\hline 588745_GH24 & CTATTT-CTTTCT-- & CCITCGTCTTAGTT & IAAATAGTTTATT \\
\hline 73323 ON8415A & CTAGTA-TTTTCT---- & & ITCTATTTTCGTC \\
\hline 73324 ON8415B & -TAATT-TTATTT-- - & CCITTATCTT & TACTTTCGTGAT \\
\hline 52633_PL-20 & -1- & & ITTAAATCTCGCT \\
\hline _LN & TTTCCTGCTGTTTGAGGGAAGTTTACCCTTCTTCTTTCGCCGCCTTTTTTAAACTTCTTTA & & TTAAATCTCGCT \\
\hline 6136_ID45 & TAACG-GTTTTT--1.-CTTTTAAACTTTTGACGTGCTTGTTTTTGAGTAGTC & & ITAGAGTTTTTAAT \\
\hline
\end{tabular}

Fig. 4. Multiple alignment of $5^{\prime}$-untranslated regions (UTRs) of representative isolates for which the complete genomes have been sequenced. GenBank accession numbers, isolate names, and nucleotide positions are provided for the isolates included in the alignment. Note that the first 40 nucleotides at the $5^{\prime}$ termini of genomes are highly conserved among isolates. 
divergent variants of GLRaV-3 (ON8415A and ON8415B), which are only distantly related to other known virus isolates (Fig. 3; $\mathrm{SF} 1$ ). Prior to this work, seven phylogenetic groups of GLRaV-3 variants had been recognized by the international grapevine virology community (Burger et al. 2017; Maree et al. 2015). As this manuscript was in the process of peer review, group IX was proposed to represent several isolates from the United States (Thompson et al. 2019). Based on the phylogenetic analyses using either full genome sequence or several individual ORFs, it is evident that isolate ON8415A is sister to the cluster of variant group VII represented by GH24 (Fig. 3; Supplementary Fig. S1. On the other hand, the grouping of $\mathrm{ON} 8415 \mathrm{~B}$ cannot be readily resolved at the present time. ON8415B can be regarded to represent a new variant group of GLRaV-3 based on two reasons. First, ON8415B is only $72.4 \%$ identical or lower in genome sequence compared with members of group IX, which is much lower than intragroup sequence identify values for any other variant groups. Second, additional partial sequences of HSP70h that are closely related to ON8415B (with sequence identities of $\sim 93 \%$ ) exist in GenBank, suggesting that similar variants are present in other regions of the world. Third, a preliminary survey and cloning work has confirmed the presence of nearly identical sequences in two other $V$. vinifera cultivars - namely, Chardonnay and Gewürztraminer (our unpublished data). Specific designation of this new viral variant group needs to be determined.

It is evident that GLRaV-3, similar to Citrus tristeza virus (a member of the genus Closterovirus that infects another woody perennial), exists as a large family of highly divergent viral variants. It is most likely that additional divergent isolates may be uncovered from grapevines that are of genotypes other than $V$. vinifera or that have been autochthonous varieties in less explored regions of the world such as Asia and the Middle East. Our preliminary HTS data from additional infected grapevine samples seem to support this hypothesis. To unify the classification system for grouping both known and additional divergent variant groups of GLRaV-3 to be identified in the future, and to avoid confusions that may arise in the literature, we call upon the international grapevine virology community to

Table 2. Comparison of nucleotide sequences of whole genome and genomic regions between isolate ON8415B and select reference isolates representing known variant groups of Grapevine leafroll-associated virus 3 (GLRaV-3) ${ }^{\mathrm{a}}$

\begin{tabular}{|c|c|c|c|c|c|c|c|c|c|c|c|c|c|c|c|c|}
\hline Isolate & Full & $5^{\prime}$-UTR & ORF1a & ORF1b & ORF2 & ORF3 & ORF4 & ORF5 & ORF6 & ORF7 & ORF8 & ORF9 & ORF10 & ORF11 & ORF12 & $3^{\prime}$-UTR \\
\hline WA-MR & 72 & 45.9 & 68.2 & 75.7 & 78.8 & 77.5 & 78.2 & 76.1 & 82.0 & 76.7 & 80.3 & 70.8 & 69.4 & 52.3 & 70.3 & 86.2 \\
\hline 623 & 72.1 & 46.5 & 68.3 & 75.9 & 75.0 & 76.1 & 78.5 & 76.0 & 81.4 & 77.3 & 79.6 & 70.8 & 70.2 & 55.0 & 70.9 & 85.8 \\
\hline PL-20 & 72 & 45.8 & 68.0 & 75.6 & 74.4 & 74.6 & 78.1 & 76.4 & 80.9 & 78.1 & 80.3 & 71.2 & 71.3 & 55.0 & 70.3 & 85.5 \\
\hline CA7246 & 67.8 & 50.4 & 67.3 & 77.1 & NA & 73.2 & 72.9 & 69.1 & 80.5 & 72.0 & 73.3 & 62.5 & 63.1 & 43.1 & 60.6 & 73.1 \\
\hline GH11 & 67.8 & 51.9 & 67.5 & 77.6 & NA & 76.1 & 73.7 & 69.2 & 80.5 & 72.0 & 74.2 & 61.0 & 66.3 & 39.4 & 64.2 & 74.1 \\
\hline $8415 \mathrm{~A}$ & 66.9 & 54.8 & 65.8 & 76.6 & NA & 72.5 & 73.8 & 69.3 & 75.5 & 67.5 & 70.6 & 56.5 & 57.8 & 45.0 & 66.7 & 69.7 \\
\hline GH24 & 66.8 & 51.1 & 65.7 & 76.1 & NA & 75.4 & 73.3 & 69.6 & 75.0 & 67.7 & 68.6 & 56.3 & 60.7 & 44.0 & 62.4 & 74.3 \\
\hline ID45 & 72.4 & 56.1 & 68.4 & 76.9 & NA & 80.4 & 79.4 & 77.8 & 81.4 & 77.7 & 78.5 & 72.5 & 74.1 & NA & 68.5 & 79.7 \\
\hline
\end{tabular}

${ }^{\text {a }}$ The whole genome and nucleotide sequences of genomic regions, open reading frames (ORFs), and terminal untranslated regions (UTRs) of isolate ON8415B were compared with their corresponding sequences of other GLRaV-3 reference isolates for which complete genome sequences are available in GenBank. Nucleotide identities are given as percentage values. Isolates CA7246, GH1 1, GH30, ON8415A, and GH24 lack ORF2; therefore, the comparisons are not available (NA).

Table 3. Comparison of amino acid sequences of open reading frames (ORFs) between isolate ON8415B and select reference isolates whose complete genome sequences are available ${ }^{\mathrm{a}}$

\begin{tabular}{|c|c|c|c|c|c|c|c|c|c|c|c|c|c|}
\hline Isolate & ORF1a & ORF1b & ORF2 & ORF3 & ORF4 & ORF5 & ORF6 & ORF7 & ORF8 & ORF9 & ORF10 & ORF11 & ORF12 \\
\hline WA-MR & 71.3 & 88.7 & 64.7 & 80.0 & 90.2 & 81.6 & 93.3 & 84.7 & 87.0 & 69.5 & 70.9 & 30.6 & 75.9 \\
\hline 623 & 71.8 & 86.9 & 54.9 & 82.2 & 90.9 & 81.2 & 92.0 & 85.5 & 87.0 & 70.1 & 68.7 & 33.3 & 75.9 \\
\hline PL-20 & 71.2 & 88.2 & 58.8 & 77.8 & 89.8 & 80.7 & 92.0 & 85.5 & 82.2 & 69.5 & 77.1 & 36.1 & 74.1 \\
\hline CA7246 & 71.4 & 89.1 & NA & 80.0 & 85.4 & 76.0 & 93.6 & 78.8 & 77.8 & 59.9 & 65.9 & 25.0 & 63.0 \\
\hline GH11 & 71.7 & 88.9 & NA & 84.4 & 85.1 & 75.2 & 96.2 & 78.8 & 78.4 & 56.5 & 68.2 & 22.2 & 64.8 \\
\hline $8415 \mathrm{~A}$ & 69.3 & 88.2 & NA & 75.6 & 84.2 & 75.6 & 90.7 & 75.3 & 73.0 & 51.9 & 51.4 & 25.0 & 59.3 \\
\hline GH24 & 69.4 & 87.2 & NA & 75.6 & 85.2 & 75.6 & 88.5 & 75.3 & 69.7 & 50.6 & 55.9 & 25.0 & 66.7 \\
\hline ID45 & 71.2 & 88.1 & & 84.8 & 89.3 & 83.9 & 92.4 & 84.1 & 80.1 & 66.9 & 75.0 & NA & 72.7 \\
\hline
\end{tabular}

${ }^{\text {a }}$ The amino acid sequence of each ORF of isolate ON8415B and those of other isolates whose complete genomes are available in GenBank were compared using the ClustalW method. Amino acid identities are given as a percentage. Isolates CA7246, GH11, GH30, ON8415A, and GH24 lack ORF2; therefore, the comparisons are not available (NA).

Table 4. Comparison of nucleotide sequences of whole genome and genomic regions between isolate ON8415A and select reference isolates representing known variant groups of Grapevine leafroll-associated virus $3(\mathrm{GLRaV}-3)^{\mathrm{a}}$

\begin{tabular}{|c|c|c|c|c|c|c|c|c|c|c|c|c|c|c|c|}
\hline Isolate & Full & $5^{\prime}$-UTR & ORF1a & ORF1b & ORF3 & ORF4 & ORF5 & ORF6 & ORF7 & ORF8 & ORF9 & ORF10 & ORF11 & ORF12 & $3^{\prime}$-UTR \\
\hline WA-MR & 66.9 & 49.5 & 65.2 & 79.1 & 69.5 & 74.2 & 69.8 & 74.8 & 69.0 & 69.2 & 57.6 & 55.2 & 38.5 & 62.1 & 74.0 \\
\hline 623 & 66.8 & 49.7 & 65.4 & 78.8 & 71.0 & 74.0 & 70.0 & 75.0 & 68.9 & 70.4 & 55.4 & 54.8 & 43.1 & 64.4 & 75.1 \\
\hline PL-20 & 67.0 & 47.9 & 65.4 & 79.4 & 67.4 & 73.0 & 70.1 & 76.5 & 68.8 & 68.8 & 57.3 & 56.1 & 42.2 & 65.0 & 75.1 \\
\hline CA7246 & 67.2 & 57.0 & 67.2 & 79.8 & 66.7 & 73.1 & 69.4 & 76.1 & 70.6 & 67.4 & 53.5 & 57.2 & 54.1 & 61.8 & 79.5 \\
\hline GH11 & 67.1 & 56.2 & 67.5 & 79.9 & 68.1 & 72.8 & 68.7 & 77.6 & 69.3 & 67.4 & 54.6 & 57.6 & 48.6 & 64.2 & 81.7 \\
\hline $8415 B$ & 66.9 & 54.8 & 65.8 & 76.6 & 72.5 & 73.8 & 69.3 & 75.5 & 67.5 & 70.6 & 56.5 & 57.8 & 45.0 & 66.7 & 69.7 \\
\hline GH24 & 76.2 & 60.1 & 75.2 & 84.4 & 72.5 & 79.6 & 76.4 & 82.7 & 76.2 & 78.3 & 75.1 & 75.0 & 64.9 & 70.0 & 90.0 \\
\hline ID45 & 67.4 & 60.6 & 67.2 & 77.0 & 71.7 & 73.5 & 69.4 & 76.0 & 66.7 & 67.4 & 58.9 & 56.9 & NA & 63.8 & 73.6 \\
\hline
\end{tabular}

${ }^{a}$ The whole genome and nucleotide sequences of genomic regions, open reading frames (ORFs), and terminal untranslated regions (UTRs) of isolate ON8415A were compared with their corresponding sequences of other GLRaV-3 reference isolates for which complete genome sequences are available in GenBank. Nucleotide sequence identities are given as percentage values. Isolate ON8415A lacks ORF2; therefore, the comparisons are not available (NA). 
assess and refine the classification system of GLRaV-3 variants in order to reflect these additional new variants.

Although the first $40 \mathrm{nt}$ of all sequenced GLRaV-3 genomes are highly conserved, a high degree of variability exists among the different isolates for which the complete genomes have been sequenced. These variations are most profound in the noncoding regions of the viral genome. For example, the $5^{\prime}$-UTR exhibits large variability in both length and sequence. They range from 642 to $802 \mathrm{nt}$, with a majority of isolates having a $5^{\prime}$-UTR of $737 \mathrm{nt}$ as first shown by Maree et al. (2008). Moreover, tandem repeats of $65 \mathrm{nt}$ were first reported in the 5'-UTR of GLRaV-3 isolates from Washington State (Jarugula et al. 2010). Here, we expand on this initial observation and reveal that these 65-nt-long tandem repeats exist in all isolates for which the genomes have been sequenced, albeit with different degrees of diversification between repeats. Similar repeats were also detected in the 5'-UTR of two other members of the genus Ampelovirus, GLRaV-1 (Donda et al. 2017) and GLRaV-13 (data not shown). GLRaV-13 contains seven copies of such tandem repeats, with 65 to $86 \%$ sequence identities among them. Interestingly, these 65 -nt repeats seem to be a hallmark for only grapevine-infecting members of the subgroup I of the genus Ampelovirus. In other words, similar repeats are not detected in GLRaV-4 and its strains, which belong to subgroup II of the genus Ampelovirus, or in any nongrapevineinfecting members of the genus. The presence of tandem repeats in GLRaV-3 and related viruses GLRaV-1 and GLRaV-13 is rather bizarre, as such a phenomenon is generally not seen in single-stranded,

Table 5. Comparison of amino acid sequences of open reading frames (ORFs) between isolate ON8415A and select reference isolates whose complete genome sequences are available

\begin{tabular}{|c|c|c|c|c|c|c|c|c|c|c|c|c|}
\hline Isolate & ORF1a & ORF1b & ORF3 & ORF4 & ORF5 & ORF6 & ORF7 & ORF8 & ORF9 & ORF10 & ORF11 & ORF12 \\
\hline WA-MR & 68.9 & 91.3 & 71.1 & 85.8 & 75.2 & 90.7 & 74.8 & 70.8 & 53.4 & 47.5 & 19.4 & 58.2 \\
\hline 623 & 69.2 & 89.6 & 73.3 & 86.2 & 75.4 & 89.8 & 75.3 & 72.4 & 51.1 & 48.6 & 25.0 & 56.9 \\
\hline PL-20 & 69.2 & 90.2 & 71.1 & 86.0 & 76.0 & 89.8 & 74.2 & 70.3 & 51.7 & 50.3 & 25.0 & 58.6 \\
\hline CA7246 & 70.9 & 91.0 & 75.6 & 83.1 & 74.3 & 90.7 & 76.1 & 69.2 & 46.0 & 48.0 & 44.4 & 53.7 \\
\hline GH11 & 71.1 & 90.8 & 75.6 & 82.7 & 72.7 & 91.4 & 74.0 & 67.6 & 45.5 & 51.4 & 36.1 & 48.1 \\
\hline $8415 B$ & 69.3 & 88.2 & 75.6 & 84.2 & 75.6 & 90.7 & 75.3 & 73.0 & 51.7 & 51.4 & 25.0 & 59.3 \\
\hline GH24 & 80.2 & 93.7 & 80.0 & 88.9 & 83.6 & 96.2 & 81.6 & 84.9 & 76.1 & 78.2 & 55.6 & 66.1 \\
\hline ID45 & 70.2 & 88.9 & 78.3 & 84.2 & 76.0 & 88.5 & 73.4 & 69.4 & 52.5 & 47.2 & NA & 59.3 \\
\hline
\end{tabular}

${ }^{a}$ The amino acid sequences of each ORF of isolate ON8415A and those of the other Grapevine leafroll-associated virus 3 (GLRaV-3) isolates are compared using the ClustalW method. Amino acid identities are given as percentage values. Isolate ON8415A lacks ORF2; therefore, no comparisons were made for ORF2 (NA).

\begin{tabular}{|l|c|c|c|c|c|}
\hline Variants & $\begin{array}{c}\text { Variant } \\
\text { groups }\end{array}$ & $\begin{array}{c}\text { Position of repeats } \\
\text { in genome }\end{array}$ & $\begin{array}{c}\text { Size of } \\
\text { repeats }\end{array}$ & $\begin{array}{c}\text { Copy number } \\
\text { of repeats }\end{array}$ & $\begin{array}{c}\text { Percent identity } \\
\text { among repeats }\end{array}$ \\
\hline WA-MR & I & $186-321$ & 65 & 2 & 92 \\
\hline 623 & II & $84-217$ & 65 & 2 & 72 \\
\hline LN & III & $149-287$ & 65 & 2 & 94 \\
\hline PL-20 & III & $116-286$ & 65 & 2.6 & 90 \\
\hline GH11 & VI & $186-321$ & 65 & 2 & 90 \\
\hline CA7246 & VI & $237-365$ & 65 & 2 & 92 \\
\hline GH24 & VII & $121-257$ & 65 & 2 & 74 \\
\hline ON8415A & TBD & $185-444$ & 65 & 4 & 81 \\
\hline ON8415B & TBD & $121-321$ & 65 & 3 & 60 \\
\hline ID45 & IX & $113-388$ & 65 & 4 & 75 \\
\hline
\end{tabular}

B Consensus \#1 TTTCCTT..T..A....AAA.A..AA.TTT.T..T..T.T.TTGTTG.GTG..GT.G..TT..G.

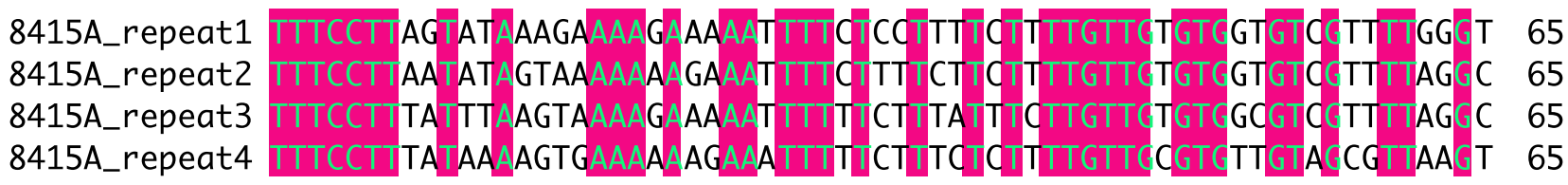

C Consensus \#1 .TT.CTAA...........A.AAAA.TA.TC..TTTT ..T...TT..T.TG..T...AG..

\section{ON8415B_repeat1 TTTCCTAAAAACTTCTAAAAGAAAAATAGTCCCTTTTTTGTTTAACTTCTATTTGCGTGGT-AGTT 65 ON8415B_repeat2 CTTTCTAAGTTCAAAAATCAAAAAATTATTCTTCTTTTTAGTCGTTTTTGTTTTGTCTAGTTAGC 65 ON8415B_repeat3 TTTCCTAAGAAAAGAAAAAACAAAAATATTCTTCTTTTGGTTTAGATTGTGTGTGTGTAAC-AGCA 65}

Fig. 5. Tandem repeats of 65 nucleotides are detected in the $5^{\prime}$-untranslated region (UTR) of Grapevine leafroll-associated virus 3 (GLRaV-3) isolates. Shown here are A, a summary of the genomic location and copy numbers of these sequence repeats as well as sequence conservation between repeats in each variant group; $\mathbf{B}$, an alignment of tandem repeats detected in ON8415A; and C, alignment of tandem repeats detected in ON8415B. Tandem repeats were identified by using the Tandem Repeats Finder Program (Benson 1999). TBD = to be determined. 
positive-sense RNA viruses. Underlying mechanisms that govern the biogenesis and biological function of these tandem repeats in these viruses remain to be deciphered.

In addition to its paramount detrimental impact on viticulture and wine making, GLRaV-3 and other members of the genus Ampelovirus present significant interest as models of plant virology. Indeed, their genomes and 5'-UTRs are among the largest known of plant viruses, they contain exceedingly long internal noncoding regions (GLRaV-1 and GLRaV-3), they encode enigmatic AlkB domains proposed to repair methylated virus RNA (van den Born et al. 2008), they target mitochondria to form the replication complexes (Faoro 1997), and there are several other proteins and genetic features of unknown function that are unique to this group of viruses. Little is known concerning how members of the Ampelovirus genus interact with their grapevine host leading to severe diseases that threaten the grape and wine industries worldwide. By expanding the knowledge of genetic diversity of GLRaV-3 within a complex vine virome, this work contributes to inquiry into GLD mechanisms, as well as to its effective control in a young and rapidly growing grape and wine industry in Canada. In closing, the two novel and divergent GLRaV-3 isolates we report here add to the repertoire of genetic diversity, phylogenetics, as well as diagnosis of this economically very important virus. GLRaV-3 and other related members of the genus Ampelovirus are truly peculiar viruses that inspire curiosity, wonder, and investigation in a wide range of directions such as viral ecology, specificity in vector transmission, as well as pathological properties of different viruses and viral strains.

\section{Literature Cited}

Aboughanem-Sabanadzovic, N., Maliogka, V., and Sabanadzovic, S. 2017. Grapevine leafroll-associated virus 4. Pages 197-220 in: Grapevine Viruses: Molecular Biology, Diagnostics and Management. B. Meng, G. P. Martelli, D. A. Golino, and M. Fuchs, eds. Springer International Publishing AG, Cham, Switzerland.

Al Rwahnih, M., Daubert, S., Golino, D., and Rowhani, A. 2009. Deep sequencing analysis of RNAs from a grapevine showing Syrah decline symptoms reveals a multiple virus infection that includes a novel virus. Virology 387:395-401.

Al Rwahnih, M., Dave, A., Anderson, M. M., Rowhani, A., Uyemoto, J. K., and Sudarshana, M. R. 2013. Association of a DNA virus with grapevines affected by red blotch disease in California. Phytopathology 103:1069-1076.

Al Rwahnih, M., Dolja, V. V., Daubert, S., Koonin, E. V., and Rowhani, A. 2012a. Genomic and biological analysis of Grapevine leafroll-associated virus 7 reveals a possible new genus within the family Closteroviridae. Virus Res. 163:302-309.

Al Rwahnih, M., Saldarelli, P., and Rowhani, A. 2017. Grapevine leafrollassociated virus 7. Pages 221-228 in: Grapevine Viruses: Molecular Biology, Diagnostics and Management. B. Meng, G. P. Martelli, D. A. Golino, and M. Fuchs, eds. Springer International Publishing AG, Cham, Switzerland.

Al Rwahnih, M., Sudarshana, M. R., Uyemoto, J. K., and Rowhani, A. 2012b. Complete genome sequence of a novel vitivirus isolated from grapevine. J. Virol. 86:9545.

Angelini, E., Aboughanem-Sabanadzovic, N., Dolja, V. V., and Meng, B. 2017. Grapevine leafroll-associated virus 2. Pages 141-165 in: Grapevine Viruses: Molecular Biology, Diagnostics and Management. B. Meng, G. P. Martelli, D. A. Golino, and M. Fuchs, eds. Springer International Publishing AG, Cham, Switzerland.

Benson, G. 1999. Tandem repeats finder: A program to analyze DNA sequences. Nucleic Acids Res. 27:573-580.

Bester, R., Maree, H. J., and Burger, J. T. 2012. Complete nucleotide sequence of a new strain of grapevine leafroll-associated virus 3 in South Africa. Arch. Virol. 157:1815-1819.

Beuve, M., Candresse, T., Tannières, M., and Lemaire, O. 2015. First report of grapevine Pinot gris virus (GPGV) in grapevine in France. Plant Dis. 99: 293.

Burger, J. T., Maree, H. J., Gouveia, P., and Naidu, R. A. 2017. Grapevine leafrollassociated virus 3. Pages 167-195 in: Grapevine Viruses: Molecular Biology, Diagnostics and Management. B. Meng, G. P. Martelli, D. A. Golino, and M. Fuchs, eds. Springer International Publishing AG, Cham, Switzerland.

Chooi, K. M., Cohen, D., and Pearson, M. N. 2013. Molecular characterisation of two divergent variants of Grapevine leafroll-associated virus 3 in New Zealand. Arch. Virol. 158:1597-1602.

Cieniewicz, E., Perry, K., and Fuchs, M. 2017. Grapevine red blotch: Molecular biology of the virus and management of the disease. Pages 303-314 in: Grapevine Viruses: Molecular Biology, Diagnostics and Management. B. Meng, G. P. Martelli, D. A. Golino, and M. Fuchs, eds. Springer International Publishing AG, Cham, Switzerland.
Coetzee, B., Freeborough, M. J., Maree, H. J., Celton, J. M., Rees, D. J., and Burger, J. T. 2010. Deep sequencing analysis of viruses infecting grapevines: Virome of a vineyard. Virology 400:157-163.

Digiaro, M., Elbeaino, T., and Martelli, G. P. 2017. Grapevine fanleaf virus and other Old World nepoviruses. Pages 47-82 in: Grapevine Viruses: Molecular Biology, Diagnostics and Management. B. Meng, G. P. Martelli, D. A. Golino, and M. Fuchs, eds. Springer International Publishing AG, Cham, Switzerland.

Dolja, V. V., Kreuze, J. F., and Valkonen, J. P. T. 2006. Comparative and functional genomics of closteroviruses. Virus Res. 117:38-51.

Dolja, V. V., Meng, B., and Martelli, G. P. 2017. Evolutionary aspects of grapevine virology. Pages 659-688 in: Grapevine Viruses: Molecular Biology, Diagnostics and Management. B. Meng, G. P. Martelli, D. A. Golino, and M. Fuchs, eds. Springer International Publishing AG, Cham, Switzerland.

Donda, B. P., Jarugula, S., and Naidu, R. A. 2017. An analysis of the complete genome sequence and subgenomic RNAs reveals unique features of the Ampelovirus, Grapevine leafroll-associated virus 1. Phytopathology 107: 1069-1079.

Engel, E. A., Girardi, C., Escobar, P. F., Arredondo, V., Dominguez, C., PerezAcle, T., and Valenzuela, P. D. 2008. Genome analysis and detection of a Chilean isolate of Grapevine leafroll associated virus-3. Virus Genes 37: 110-118.

Fajardo, T. V. M., Silva, F. N., Eiras, M., and Nickel, O. 2017. High-throughput sequencing applied for the identification of viruses infecting grapevines in Brazil and genetic variability analysis. Trop. Plant Pathol. 42:250-260.

Faoro, F. 1997. Cytopathology of closteroviruses and trichoviruses infecting grapevines. Pages 29-47 in: Filamentous Viruses of Woody Plants. Monette, P. L. ed. Research Signpost, Trivandrum, India.

Fei, F., Lyu, M. D., Li, J., Fan, Z. F., and Cheng, Y. Q. 2013. Complete nucleotide sequence of a Chinese isolate of Grapevine leafroll-associated virus 3 reveals a $5^{\prime}$ UTR of 802 nucleotides. Virus Genes 46:182-185.

Giampetruzzi, A., Roumi, V., Roberto, R., Malossini, U., Yoshikawa, N., La Notte, P., Terlizzi, F., Credi, R., and Saldarelli, P. 2012. A new grapevine virus discovered by deep sequencing of virus- and viroid-derived small RNAs in Cv Pinot gris. Virus Res. 163:262-268.

Glasa, M., Predajňa, L., Komínek, P., Nagyová, A., Candresse, T., and Olmos, A. 2014. Molecular characterization of divergent grapevine Pinot gris virus isolates and their detection in Slovak and Czech grapevines. Arch. Virol. 159:2103-2107.

Glasa, M., Predajňa, L., Saltys, K., Siheksjam, N., Nagyová, A., Wetzel, T., and Sabanadzovic, S. 2017. Analysis of Grapevine rupestris stem pittingassociated virus in Slovakia reveals differences in intra-host population diversity and naturally occurring recombination events. Plant Pathol. J. 33: 34-42.

Goszczynski, D. E. 2007. Single-stranded conformation polymorphism (SSCP) cloning and sequencing reveal a close association between related molecular variants of Grapevine virus A (GVA) and Shiraz disease in South Africa. Plant Pathol. 56:755-762.

Goszczynski, D. E. 2014. Complete genome sequence of a natural mutant of grapevine virus A (GVA). Arch. Virol. 159:2523-2528.

Jarugula, S., Gowda, S., Dawson, W. O., and Naidu, R. A. 2010. 3'-coterminal subgenmic RNAs and putative cis-acting elements of Grapevine leafrollassociated virus 3 reveals 'unique' features of gene expression strategy in the genus Ampelovirus. Virol. J. 7:180.

Jo, Y., Choi, H., Cho, J. K., Yoon, Y. Y., Choi, S. K., and Cho, W. K. 2015. In silico approach to reveal viral populations in grapevine cultivar Tannat using transcriptome data. Sci. Rep. 5:15841.

Jooste, A. E. C., Maree, H. J., Bellstedt, D. U., Goszczynski, D. E., Pietersen, G., and Burger, J. T. 2010. Three genetic grapevine leafroll-associated virus 3 variants identified from South African vineyards show high variability in their 5' UTR. Arch. Virol. 155:1997-2006.

MacKenzie, D. J., Johnson, R. C., and Warner, C. 1996. Incidence of four important viral pathogens in Canadian vineyards. Plant Dis. 80:955-958.

Maliogka, V. I., Olmos, A., Pappia, P. G., Lotosa, L., Efthimiou, K., Grammatikaki, G., Candresse, T., Katis, N. I., and Avgelis, A. D. 2015. A novel grapevine badnavirus is associated with the Roditis leaf discoloration disease. Virus Res. 203:47-55.

Mannini, F., and Digiaro, M. 2017. The effects of viruses and viral diseases on grapes and wine. Pages 453-482 in: Grapevine Viruses: Molecular Biology, Diagnostics and Management. B. Meng, G. P. Martelli, D. A. Golino, and M. Fuchs, eds. Springer International Publishing AG, Cham, Switzerland

Maree, H. J., Almeida, R. P., Bester, R., Chooi, K., Cohen, D., Dolja, V. V., Fuchs, M. F., Golino, D. A., Jooste, A. E., Martelli, G. P., Naidu, R. A., Rowhani, A., Saldarelli, P., and Burger, J. 2013. Grapevine leafroll-associated virus 3. Front. Microbiol. 4:82.

Maree, H. J., Freeborough, M.-J., and Burger, J. T. 2008. Complete nucleotide sequence of a South African isolate of grapevine leafroll-associated virus 3 reveals a 5'UTR of 737 nucleotides. Arch. Virol. 153:755-757.

Maree, H. J., Pirie, M. D., Oosthuizen, K., Bester, R., Rees, D. J. G., and Burger, J. T. 2015. Phylogenomic analysis reveals deep divergence and recombination in an economically important grapevine virus. PLoS One 10:e0126819.

Martelli, G. P. 2017. An overview on grapevine viruses, viroids and the diseases they cause. Pages 31-46 in: Grapevine Viruses: Molecular Biology, 
Diagnostics and Management. B. Meng, G. P. Martelli, D. A. Golino, and M. Fuchs, eds. Springer International Publishing AG, Cham, Switzerland.

Martelli, G. P. 2018. Where grapevine virology is heading to. Pages 10-15 in: Proceedings of the 19th Congress of the International Council for the Study of Virus and Virus-like Diseases of the Grapevine; Santiago, Chile; 9-12 April 2018.

Martelli, G. P., Ghanem-Sabanadzovic, N. A., Agranovsky, A., Al Rwahnih, M., Dolja, V. V., Dovas, C. I., Fuchs, M., Gugerli, P., Hu, J. S., Jelkmann, W., Katis, N. I., Maliogka, V. I., Melzer, M. J., Menzel, W., Minafra, A., Rott, M. E., Rowhani, A., Sabanadzovic, S., and Saldarelli, P. 2012. Taxonomic revision of the family Closteroviridae with special reference to the grapevine leafroll-associated members of the genus Ampelovirus and the putative species unassigned to the family. J Plant Path. 94:7-19.

Meng, B., and Rowhani, A. 2017. Grapevine rupestris stem pitting-associated virus. Pages 257-287 in: Grapevine Viruses: Molecular Biology, Diagnostics and Management. B. Meng, G. P. Martelli, D. A. Golino, and M. Fuchs, eds. Springer International Publishing AG, Cham, Switzerland.

Minafra, A., Mawassi, M., Goszczynski, D., and Saldarelli, P. 2017. Grapevine vitiviruses. Pages 229-256 in: Grapevine Viruses: Molecular Biology, Diagnostics and Management. B. Meng, G. P. Martelli, D. A. Golino, and M. Fuchs, eds. Springer International Publishing AG, Cham, Switzerland.

Naidu, R., Rowhani, A., Fuchs, M., Golino, D., and Martelli, G. P. 2014. Grapevine leafroll: A complex viral disease affecting a high-value fruit crop. Plant Dis. 98:1172-1185.

Naidu, R. A. 2017. Grapevine leafroll-associated virus 1. Pages 127-139 in: Grapevine Viruses: Molecular Biology, Diagnostics and Management. B. Meng, G. P. Martelli, D. A. Golino, and M. Fuchs, eds. Springer International Publishing AG, Cham, Switzerland.

Navarro, B., Pantaleo, V., Gisel, A., Moxon, S., Dalmay, T., Bisztray, G., Di Serio, F., and Burgyán, J. 2009. Deep sequencing of viroid-derived small RNAs from grapevine provides new insights on the role of RNA silencing in plant-viroid interaction. PLoS One 4:e7686.

Pantaleo, V., Saldarelli, P., Miozzi, L., Giampetruzzi, A., Gisel, A., Moxon, S., Dalmay, T., Bisztray, G., and Burgyan, J. 2010. Deep sequencing analysis of viral short RNAs from an infected Pinot Noir grapevine. Virology 408: 49-56.

Poojari, S., Alabi, O. J., Fofanov, V. Y., and Naidu, R. A. 2013. A leafhoppertransmissible DNA virus with novel evolutionary lineage in the family Geminiviridae implicated in grapevine redleaf disease by next-generation sequencing (correction published in PLoS One. 2016;11:e0147510). PLoS One 8:e64194

Poojari, S., Boulé, J., DeLury, N., Lowery, D. T., Rott, M., Schmidt, A. M., and Urbez-Torres, J. R. 2017b. Epidemiology and genetic diversity of grapevine leafroll-associated viruses in British Columbia. Plant Dis. 101:2088-2097.

Poojari, S., Lowery, D. T., Rott, M., Schmidt, A. M., and Úrbez-Torres, J. R. 2017a. Incidence, distribution and genetic diversity of Grapevine red blotch virus in British Columbia. Can. J. Plant Pathol. 39:201-211.

Rowhani, A., Daubert, S. D., Uyemoto, J. K., Al Rwahnih, M., and Fuchs, M. 2017. American nepoviruses. Pages 109-126 in: Grapevine Viruses Molecular Biology, Diagnostics and Management. B. Meng, G. P. Martelli, D. A. Golino, and M. Fuchs, eds. Springer International Publishing AG, Cham, Switzerland.

Saldarelli, P., Gualandri, V., Malossini, U., and Glasa, M. 2017. Grapevine Pinot gris virus. Pages 351-363 in: Grapevine Viruses: Molecular Biology, Diagnostics and Management. B. Meng, G. P. Martelli, D. A. Golino, and M. Fuchs, eds. Springer International Publishing AG, Cham, Switzerland.

Saldarelli, P., Minafra, A., and Martelli, G. P. 1996. The nucleotide sequence and genomic organization of Grapevine virus B. J. Gen. Virol. 77:2645-2652.

Thompson, B., Dahan, J., Lee, J., Martin, R. R., and Karasev, A. V. 2019. A novel genetic variant of Grapevine leafroll-associated virus 3 (GLRaV-3) from Idaho grapevines. Plant Dis. Epub 22 Jan 2019. doi.org/10.1094/PDIS-08-18-1303-RE

van den Born, E., Omelchenko, M. V., Bekkelund, A., Leihne, V., Koonin, E. V., Dolja, V. V., and Falnes, P. Ø. 2008. Viral AlkB proteins repair RNA damage by oxidative demethylation. Nucleic Acids Res. 36:5451-5461.

Velasco, L., Bota, J., Montero, R., and Cretazzo, E. 2014. Differences of three ampeloviruses' multiplication in plant may explain their incidences in vineyards. Plant Dis. 98:395-400.

Wang, J., Sharma, A. M., Duffy, S., and Almeida, R. P. P. 2011. Genetic diversity in the $3^{\prime}$ terminal 4.6-kb region of Grapevine leafroll associated virus 3 . Phytopathology 101:445-450.

Xiao, H., Kim, W.-S., and Meng, B. 2015. A highly effective and versatile technology for the isolation of RNAs from grapevines and other woody perennials for use in virus diagnostics. Virol. J. 12:171.

Xiao, H., Shabanian, M., Moore, C., Li, C., and Meng, B. 2018. Survey for major viruses in commercial Vitis vinifera wine grapes in Ontario. Virol. J. 15:127.

Zhang, Y., Singh, K., Kaur, R., and Qiu, W. 2011. Association of a novel DNA virus with the grapevine vein-clearing and vine decline syndrome. Phytopathology 101:1081-1090. 